\title{
First-Line Doublet Chemotherapy for Metastatic Triple-Negative Breast Cancer: Circulating Tumor Cell Analysis of the tnAcity Trial
}

This article was published in the following Dove Press journal: Cancer Management and Research

\author{
Minetta C Liu' \\ Wolfgang Janni ${ }^{2}$ \\ Vassilis Georgoulias ${ }^{3}$ \\ Denise A Yardley ${ }^{4}$ \\ Nadia Harbeck (iD ${ }^{5}$ \\ Xin $\mathrm{Wei}^{6}$ \\ Desmond McGovern ${ }^{7}$ \\ Robert Beck (iD) ${ }^{7}$ \\ 'Department of Laboratory Medicine and \\ Pathology, Mayo Clinic, Rochester, MN, \\ USA; ${ }^{2}$ Department of Obstetrics and \\ Gynecology, University Clinic Ulm, Ulm, \\ Germany; ${ }^{3}$ Department of Medical \\ Oncology, School of Medicine, University \\ of Crete, Crete, Greece; ${ }^{4}$ Department of \\ Medical Oncology, Breast Cancer \\ Research Program, Sarah Cannon \\ Research Institute, Nashville, TN, USA; \\ ${ }^{5}$ Department of Breast Center, \\ Oncological Therapy and Clinical Trials \\ Unit, University of Munich (LMU), \\ Munich, Germany; ${ }^{6}$ Department of \\ Translational/Clinical Development, \\ Celgene Corporation, Summit, NJ, USA; \\ ${ }^{7}$ Department of Clinical Research, \\ Celgene Corporation, Summit, NJ, USA
}

Correspondence: Minetta C Liu

Department of Laboratory Medicine and

Pathology, Mayo Clinic, 200 First St SW,

Rochester, MN 55905, USA

Tel + I 5072930526

Email Liu.Minetta@mayo.edu
Purpose: Circulating tumor cells (CTCs) are prognostic biomarkers in metastatic breast cancer, but their role in predicting treatment outcomes in metastatic triple-negative breast cancer (mTNBC) is less clear. The tnAcity trial demonstrated a significant progression-free survival (PFS) benefit with $n a b$-paclitaxel (nab-P)/carboplatin (C) over $n a b$-P/gemcitabine (G) or $\mathrm{G} / \mathrm{C}$ in patients with mTNBC. We assessed the correlation between CTC dynamics and clinical benefit in all patients and by treatment arm.

Methods: CTC enumeration, performed using CELLSEARCH technology (Menarini Silicon Biosystems, Huntingdon Valley, PA, USA), was a prespecified exploratory endpoint in the tnAcity trial. Patients with TNBC were categorized based on pre- and post-treatment CTC levels: Group $1(+++$; elevated CTCs at baseline and postbaseline), Group $2(+ \pm \pm$; CTCs elevated at baseline and cleared postbaseline [cycle 3 and/or cycle 5]), or Group 3 (-; no CTCs detected at baseline). The baseline cutoff was $\geq 1 \mathrm{CTC} / 7.5 \mathrm{~mL}$ for the main analysis; cutoffs of $\geq 2$ and $\geq 5$ CTCs were used for supporting analyses.

Results: The main analysis included 126 patients (Group 1, $\mathrm{n}=24$; Group 2, $\mathrm{n}=54$; and Group 3, $\mathrm{n}=48$ ). The median PFS was longer in Group 2 vs Group 1 (8.5 vs 4.7 months; HR, 0.30 [95\% CI, $0.17-0.54]$ ). These results were supported by the $\geq 2$ - and $\geq 5$-CTC cutoff analyses. The median overall survival rates were 17.8, 16.0, and 9.8 months in Groups 2, 3, and 1, respectively. The overall response rates were $79.6 \%, 43.8 \%$, and $29.2 \%$, respectively. A numerically higher percentage of patients had CTC clearance during $n a b-\mathrm{P} / \mathrm{C}$ treatment vs $n a b-\mathrm{P} / \mathrm{G}$ or $\mathrm{G} / \mathrm{C}$.

Conclusion: Efficacy outcomes trended positively with chemotherapy-induced elimination of CTCs, suggesting that CTC clearance may predict the chemosensitivity of mTNBC tumors.

Trial registration: EudraCT Number: 2013-000113-20; ClinicalTrials.gov number: NCT01881230.

Keywords: metastatic triple-negative breast cancer, circulating tumor cells, nab-paclitaxel, chemotherapy, prognosis

\section{Introduction}

Circulating tumor cell (CTC) enumeration is gaining importance in cancer therapy due to its potential to guide prognosis and treatment, measure tumor burden and response to treatment, and detect recurrent disease. ${ }^{1}$ The prognostic value of CTCs has been established in studies of patients with both early-stage and metastatic breast cancer $(\mathrm{MBC}){ }^{2,3}$

CELLSEARCH technology (Menarini Silicon Biosystems, Huntingdon Valley, PA, USA) has been cleared by the US Food and Drug Administration as an aid in 
monitoring patients with $\mathrm{MBC}$, colorectal cancer, or prostate cancer. ${ }^{4}$ Prospective studies using CELLSEARCH have demonstrated that patients with $\mathrm{MBC}$ and $\geq 5 \mathrm{CTCs} / 7.5 \mathrm{~mL}$ of blood at baseline have shorter progression-free survival (PFS) and overall survival (OS) than those with $<5$ CTCs. Moreover, CTC clearance during treatment (a decrease from $\geq 5$ CTCs at baseline to $<5$ CTCs postbaseline) has been associated with improved outcomes compared with no clearance ( $\geq 5$ CTCs at all time points, including baseline). ${ }^{5,6}$ These findings have been confirmed by prospective and pooled analyses with larger patient numbers. ${ }^{7-9}$

A recent prospective CTC study included a subset of patients with hormone receptor-negative, human epidermal growth factor receptor 2 (HER2)-negative breast cancer (triple-negative breast cancer [TNBC]). In that study, it was reported that OS outcomes were best in patients with low CTCs at baseline ( $<5 \mathrm{CTCs} / 7.5 \mathrm{~mL})$, followed by those who experienced a reduction in CTCs upon treatment (a decrease to $<5$ CTCs from baseline). OS outcomes were worst among patients with CTCs unresponsive to therapy (persistent increase of $\geq 5$ CTCs postbaseline). ${ }^{10}$

The multicenter, open-label, randomized, Phase II/III tnAcity trial evaluated the efficacy and safety of 3 chemotherapy regimens (nab-paclitaxel [nab-P]/carboplatin [C], nab-P/gemcitabine [G], and $\mathrm{G} / \mathrm{C}$ ) as first-line treatment for patients with metastatic TNBC (mTNBC). ${ }^{11} n a b-$ $\mathrm{P} / \mathrm{C}$ treatment resulted in a significantly longer median PFS and numerically higher overall response rate (ORR) compared with $n a b-\mathrm{P} / \mathrm{G}$ or $\mathrm{G} / \mathrm{C}$; grade $\geq 3$ adverse events were mainly hematologic. ${ }^{12}$ The findings of a prespecified exploratory analysis investigating the correlation of CTC levels with ORR, PFS, and OS are reported here.

\section{Materials and Methods}

\section{Study Design and Patients}

The tnAcity trial investigated weekly treatment with $n a b-\mathrm{P} / \mathrm{C}$

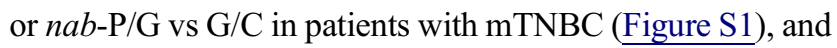
the study design has been previously reported. ${ }^{12}$ Briefly, key eligibility requirements included measurable metastatic disease per Response Evaluation Criteria In Solid Tumors (RECIST) version 1.1, Eastern Cooperative Oncology Group performance status (ECOG PS) $\leq 1$, and prior adjuvant or neoadjuvant anthracycline therapy (unless not indicated by physician).

The trial was registered at ClinicalTrials.gov (NCT01 881230), approved by institutional review boards or independent ethics committees at each of the 52 participating sites
(Table S1), and conducted in accordance with the Declaration of Helsinki and Good Clinical Practice Guidelines of the International Conference on Harmonisation. All patients provided written informed consent prior to study entry.

\section{Endpoints and Study Assessments}

The primary endpoint of Phase II was investigator-assessed PFS per RECIST 1.1. Secondary endpoints included investigator-assessed ORR, OS, and safety. CTC enumeration was a prespecified exploratory endpoint. CTCs were measured before treatment on day 1 of cycle 1 (baseline) and day 1 of cycles 3 and 5 (postbaseline). Briefly, 8 to $10 \mathrm{~mL}$ of whole blood was collected in a CellSave blood collection tube (Menarini Silicon Biosystems). CTC enrichment and enumeration were performed using the CELLSEARCH CTC Test according to the manufacturer's instructions.

The standard, established CTC cutoff in the MBC setting is 5 CTCs. ${ }^{4,5}$ A cutoff of $\geq 1$ CTC was used for the main analysis of the current study because it increased the sensitivity of the analysis. Cutoffs of $\geq 2$ and $\geq 5$ CTCs were used for supportive analyses. All CTC cutoffs and values are reported per $7.5 \mathrm{~mL}$ of blood. For analyses by CTC clearance, patients were classified into 3 groups according to presence of CTCs at baseline and change in CTC levels postbaseline: Group $1(+++$; CTCs elevated at baseline and both postbaseline visits), Group $2(+ \pm \pm$; CTCs elevated at baseline and cleared at $\geq 1$ postbaseline visit), and Group 3 (-; no CTCs at baseline) (Table S2). In additional analyses, patients were grouped exclusively by the presence or absence of CTCs at baseline.

\section{Statistical Methods}

The Kaplan-Meier method was used to estimate the distribution of PFS and OS with a log-rank test. The KaplanMeier curves were presented individually for each group. The hazard ratio (HR) between these groups and the associated 2 -sided $95 \%$ CI were estimated using a Cox proportional hazards model.

\section{Results}

\section{Patients and Baseline CTC Levels}

A total of 191 patients were enrolled in the tnAcity trial, $^{12}$ and 126 patients were included in the main analysis ( $\geq 1$-CTC cutoff; 24,54 , and 48 patients were included in Groups 1, 2, and 3, respectively). Across the 3 groups, most patients were aged $<65$ years and had an ECOG PS of 0 (Table 1). In the $\geq 2$-CTC cutoff analysis, 
Table I Patient Baseline Characteristics in the Main Analysis of $\geq$ I Circulating Tumor Cell

\begin{tabular}{|c|c|c|c|}
\hline Characteristic & $\begin{array}{l}\text { Group I } \\
(+++) \\
n=24\end{array}$ & $\begin{array}{l}\text { Group } 2 \\
(+ \pm \pm) \\
n=54\end{array}$ & $\begin{array}{l}\text { Group } 3 \\
(-) \\
n=48\end{array}$ \\
\hline $\begin{array}{l}\text { Age, median (range), years } \\
\quad<65, \mathrm{n}(\%) \\
\geq 65, \mathrm{n}(\%)\end{array}$ & $\begin{array}{l}57.0 \\
(27-7 \mid) \\
15(62.5) \\
9(37.5)\end{array}$ & $\begin{array}{l}56.0 \\
(27-74) \\
42(77.8) \\
12(22.2)\end{array}$ & $\begin{array}{l}56.5 \\
(31-82) \\
32(66.7) \\
16(33.3)\end{array}$ \\
\hline $\begin{array}{l}\text { Baseline ECOG PS, n (\%) } \\
0 \\
1 \\
2\end{array}$ & $\begin{array}{l}15(62.5) \\
9(37.5) \\
0\end{array}$ & $\begin{array}{l}30(55.6) \\
24(44.4) \\
0\end{array}$ & $\begin{array}{l}31(64.6) \\
16(33.3) \\
I(2.1)\end{array}$ \\
\hline $\begin{array}{l}\text { Race, } n(\%) \\
\text { White } \\
\text { Black/African American } \\
\text { Not collected or reported }\end{array}$ & $\begin{array}{l}18(75.0) \\
4(16.7) \\
2(8.3)\end{array}$ & $\begin{array}{l}49(90.7) \\
3(5.6) \\
2(3.7)\end{array}$ & $\begin{array}{l}37(77.1) \\
7(14.6) \\
4(8.3)\end{array}$ \\
\hline $\begin{array}{l}\text { Region, n (\%) } \\
\text { North America } \\
\text { Western Europe } \\
\text { Australia }\end{array}$ & $\begin{array}{l}\text { I } 3(54.2) \\
\text { I I (45.8) } \\
0\end{array}$ & $\begin{array}{l}33(6 \mathrm{I} .1) \\
20(37.0) \\
I(1.9)\end{array}$ & $\begin{array}{l}23(47.9) \\
25(52.1) \\
0\end{array}$ \\
\hline $\begin{array}{l}\text { Disease-free interval, } n(\%) \\
\quad \leq 1 \text { year } \\
\quad>\text { I year }\end{array}$ & $\begin{array}{l}7(29.2) \\
17(70.8)\end{array}$ & $\begin{array}{l}12(22.2) \\
41(75.9)\end{array}$ & $\begin{array}{l}14(29.2) \\
34(70.8)\end{array}$ \\
\hline $\begin{array}{l}\text { Triple negative at primary } \\
\text { diagnosis, } \mathrm{n}(\%)\end{array}$ & $17(70.8)$ & $45(83.3)$ & $35(72.9)$ \\
\hline $\begin{array}{l}\text { Site of metastasis, } n \text { (\%) } \\
\text { Bone } \\
\text { Breast } \\
\text { Liver } \\
\text { Lung/thoracic } \\
\text { Lymph node(s) } \\
\text { Skin/soft tissue } \\
\text { Other } \\
\text { Abdomen/peritoneal }\end{array}$ & $\begin{array}{l}12(50.0) \\
7(29.2) \\
9(37.5) \\
11(45.8) \\
18(75.0) \\
5(20.8) \\
4(16.7) \\
2(8.3)\end{array}$ & $\begin{array}{l}21(38.9) \\
18(33.3) \\
17(31.5) \\
33(61.1) \\
45(83.3) \\
10(18.5) \\
9(16.7) \\
2(3.7)\end{array}$ & $\begin{array}{l}13(27.1) \\
7(14.6) \\
10(20.8) \\
35(72.9) \\
28(58.3) \\
8(16.7) \\
10(20.8) \\
0\end{array}$ \\
\hline Prior taxane treatment, $\mathrm{n}(\%)$ & $17(70.8)$ & $29(53.7)$ & $33(68.8)$ \\
\hline
\end{tabular}

Abbreviation: ECOG PS, Eastern Cooperative Oncology Group performance status.

16, 44, and 69 patients were included in Groups 1, 2, and 3 , respectively, while the $\geq 5$-CTC cutoff analysis included 10, 34, and 87 patients, respectively (Tables S3 and $\underline{\mathrm{S}}$ ).

At baseline, the median CTC level in Group 1 was 21.5, with levels of 3.0 and 9.8 at cycles 3 and 5, respectively (Table 2). In Group 2, patients had a median of 5.0 CTCs at baseline, and 0 CTCs were detected at cycles 3 and 5. Patients in Group 3 had no CTCs detected at baseline.
Table 2 Median Circulating Tumor Cell Values at Each Assessment

\begin{tabular}{|l|l|l|l|}
\hline $\begin{array}{l}\text { Assessment, Median } \\
\text { (Range), CTCs/7.5 mL } \\
\text { Blood }\end{array}$ & $\begin{array}{l}\text { Group I } \\
(+++)\end{array}$ & $\begin{array}{l}\text { Group 2 } \\
(+ \pm \pm)\end{array}$ & $\begin{array}{l}\text { Group } \\
\mathbf{3}(-)\end{array}$ \\
\hline Baseline & $\begin{array}{l}\mathrm{n}=24 \\
21.5 \\
(0.5-478.5)\end{array}$ & $\begin{array}{l}\mathrm{n}=5.0 \\
(0.5-1211.5)\end{array}$ & $\begin{array}{l}\mathrm{n}=48 \\
0\end{array}$ \\
\hline Cycle 3 & $\mathrm{n}=18$ & $\begin{array}{l}\mathrm{n}=52 \\
0(0-3.0)\end{array}$ & $\begin{array}{l}\mathrm{n}=46 \\
0 \\
(0-19.0)\end{array}$ \\
\hline Cycle 5 & $\begin{array}{l}0.5-169.0) \\
\mathrm{n}=14\end{array}$ & $\begin{array}{l}\mathrm{n}=50 \\
0(0-17.5)\end{array}$ & $\begin{array}{l}\mathrm{n}=24 \\
0 \\
(0-3.0)\end{array}$ \\
\hline
\end{tabular}

Abbreviation: CTC, circulating tumor cell.

\section{Efficacy}

Patients in Group 2 had the highest ORR (79.6\%), followed by Group 3 (43.8\%) and Group 1 (29.2\%) (Table 3). Patients in Group 2 also had a longer median PFS compared with Group 1 (8.5 vs 4.7 months; HR, 0.30 [95\% CI, 0.17-0.54]; Figure 1A). The median PFS was 5.9 months in Group 3. Compared with Group 1 (9.8 months), the median OS was longer in both Groups 2 (17.8 months; HR, 0.35 [95\% CI, 0.20-0.62]) and 3 (16.0 months; HR, 0.40 [95\% CI, 0.22-0.73]; Figure 1B).

The ORR and PFS results were supported by the $\geq 2$ and $\geq 5$-CTC cutoff analyses (Table S5). In the $\geq 2$-CTC cutoff analysis, patients in Group 2 had a higher ORR (77.3\%) compared with Group 3 (47.8\%) and Group 1 (31.3\%). In the same analysis, the median PFS was 8.9 months in Group 2 and 6.0 months in Group 3 vs 4.7 months in Group 1, and the median OS was 16.8 months in Group 2 and 16.2 months in Group 3 vs 9.8 months in Group 1. Similarly, in the $\geq 5$-CTC cutoff analysis, the ORRs were $82.4 \%, 48.3 \%$, and $20.0 \%$ in Groups 2,3 , and 1 , respectively. The median PFS rates were 8.4, 6.5, and 4.7 months, respectively. Patients in Group 3 had the

Table 3 Response by Change in Circulating Tumor Cell (CTC) Levels from Baseline in the Main Analysis of $\geq 1$ CTC

\begin{tabular}{|c|c|c|c|}
\hline Response, n (\%) & $\begin{array}{l}\text { Group I } \\
(+++) \\
n=24\end{array}$ & $\begin{array}{l}\text { Group } 2 \\
(+ \pm \pm) \\
n=54\end{array}$ & $\begin{array}{l}\text { Group } 3 \\
(-) n=48\end{array}$ \\
\hline Overall response rate & $7(29.1)$ & $43(79.6)$ & $21(43.8)$ \\
\hline Complete response & I (4.2) & $9(16.7)$ & $3(6.3)$ \\
\hline Partial response & $6(25.0)$ & $34(63.0)$ & $18(37.5)$ \\
\hline
\end{tabular}




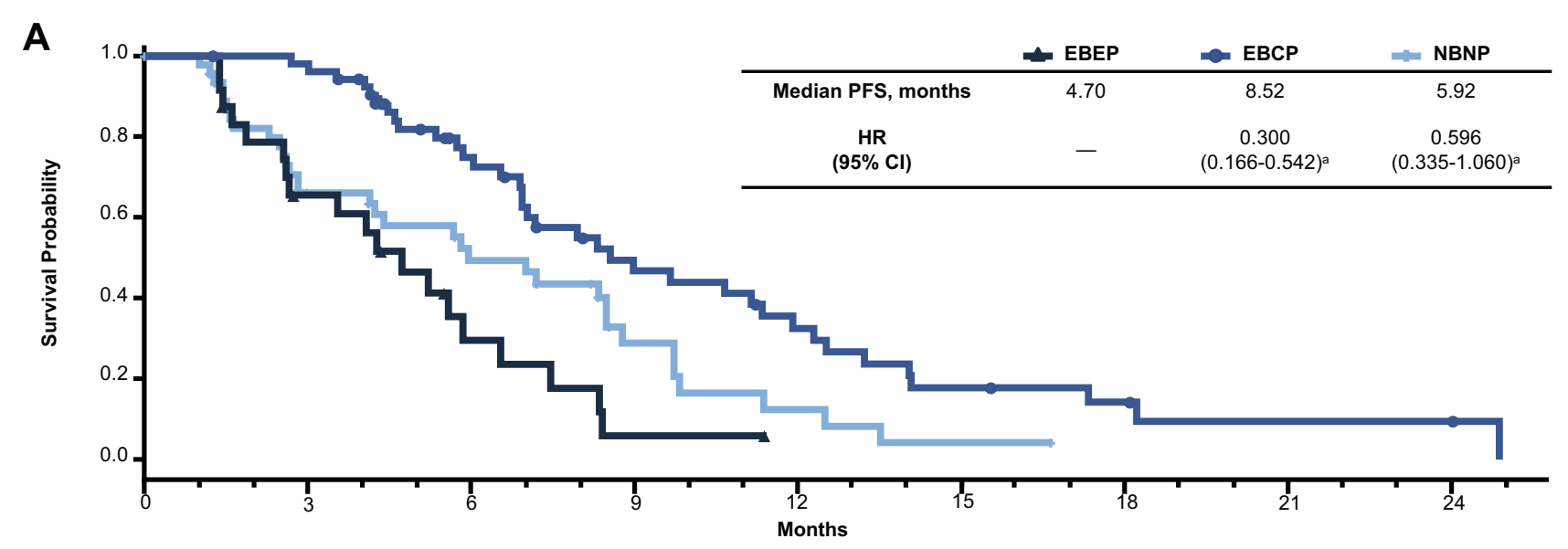

B

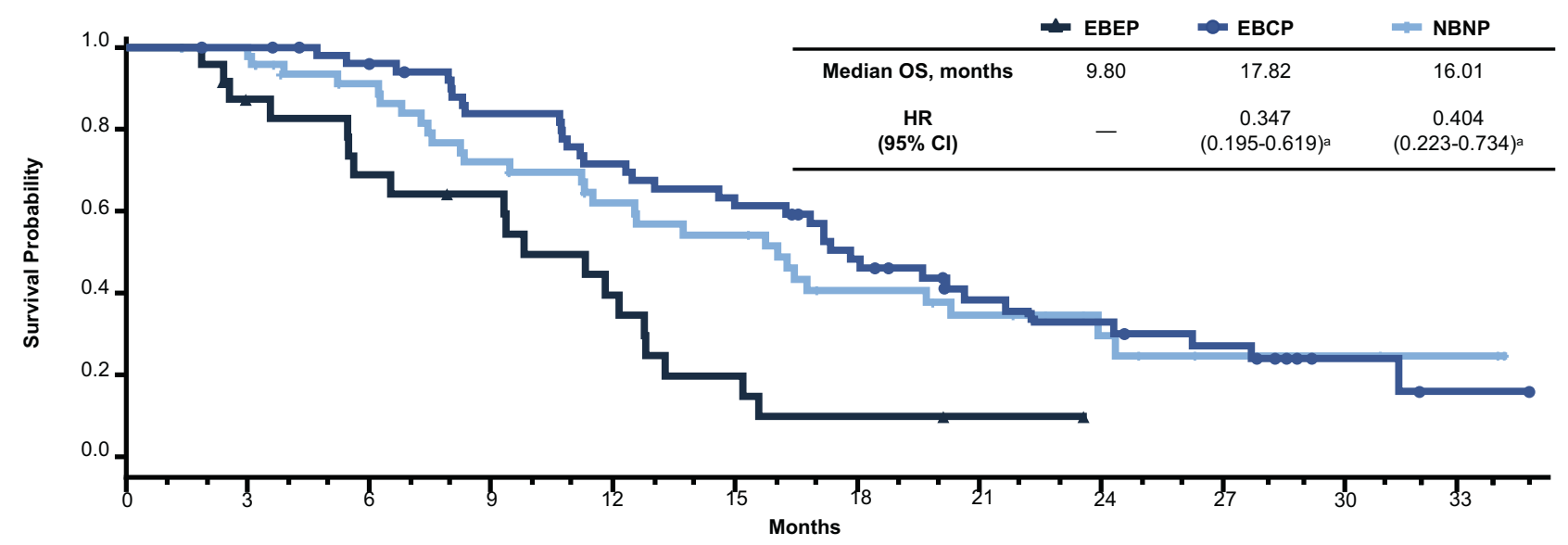

Figure I Efficacy outcomes by change in circulating tumor cell levels from baseline. Kaplan-Meier plots of (A) PFS and (B) OS.

Notes: Group I (+++), elevated at baseline and elevated postbaseline; Group $2(+ \pm \pm$ ), elevated at baseline and cleared postbaseline (cycle 3 and/or cycle 5); Group $3(-)$, no CTCs detected at baseline. ${ }^{a}$ vs Group I.

Abbreviations: HR, hazard ratio; OS, overall survival; PFS, progression-free survival.

longest median OS (16.0 months), followed by Group 2 (15.4 months) and Group 1 (9.8 months) (Table S5).

\section{Efficacy by Baseline CTC Levels}

An efficacy analysis based on the presence or absence of CTCs at baseline revealed that patients with 0 detected CTCs at baseline had a lower ORR (43.8\%) than those with $\geq 1$ CTC at baseline (64.1\%). The median PFS (5.9 vs 7.0 months; HR, 1.45 [95\% CI, 0.93-2.25]; Figure 2A) and OS (16.0 vs 15.0 months; HR, 0.90 [95\% CI, 0.57-1.42]; Figure 2B) were similar for patients with $0 \mathrm{vs} \geq 1 \mathrm{CTC}$ at baseline, respectively. Additional analyses using cutoffs of $\geq 2$ and $\geq 5$ CTCs at baseline support these results (Table S6).

\section{Efficacy by Treatment Group}

An analysis of CTC dynamics by treatment received showed that more patients in the $n a b-\mathrm{P} / \mathrm{C}$ arm had postbaseline CTC clearance (Group 2) than in the $n a b-\mathrm{P} / \mathrm{G}$ and $\mathrm{G} / \mathrm{C}$ arms $(60.0 \%$ vs $28.2 \%$ vs $38.1 \%$; Table 4$)$. In general, patterns of PFS were similar regardless of treatment arm, with numerically longer median PFS values associated with Groups 2 and 3 compared with Group 1; however, no formal statistical analyses were performed to support this comparison. These results were supported in the $\geq 2$ - and $\geq 5$-CTC cutoff analyses (Table S7).

\section{Discussion}

The tnAcity CTC analysis revealed better efficacy outcomes in patients with CTC clearance. A numerically higher percentage of patients in the $n a b-\mathrm{P} / \mathrm{C}$ arm experienced CTC clearance during treatment than in the $n a b-\mathrm{P} / \mathrm{G}$ and $\mathrm{G} / \mathrm{C}$ arms, suggesting improved antitumor activity with $n a b$-P/C. We report the results with $\geq 1-, \geq 2$-, and $\geq 5$-CTC cutoffs, but to increase the sensitivity of our 


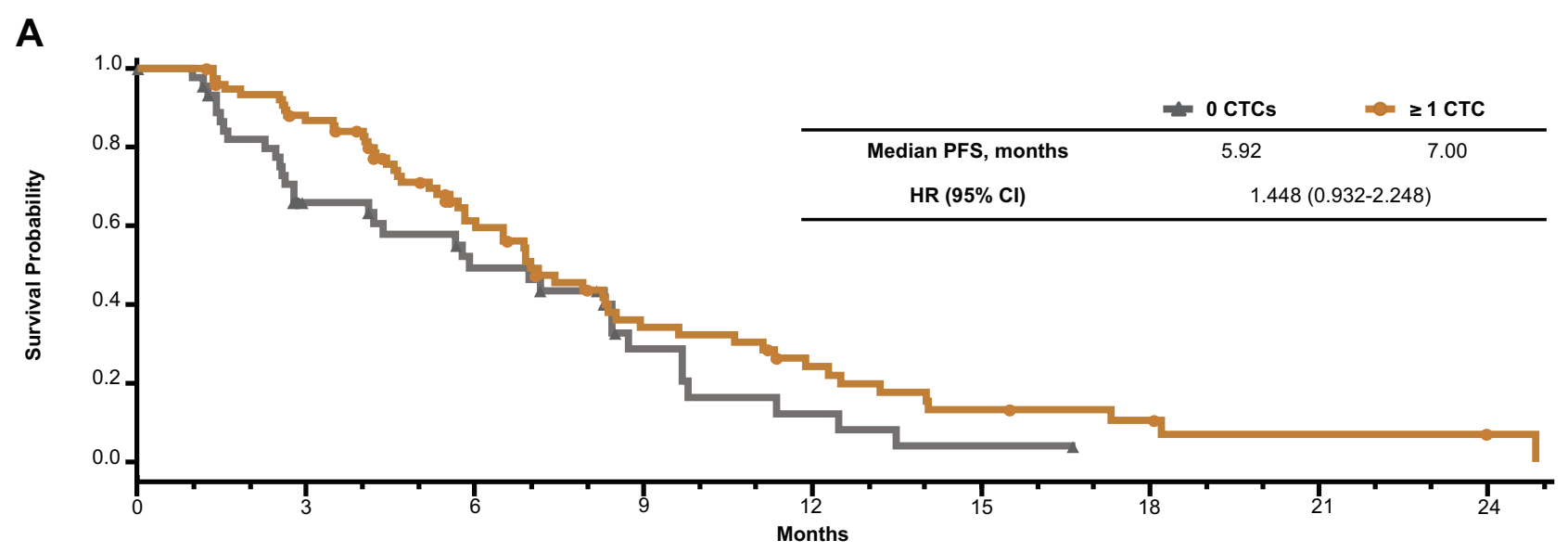

B

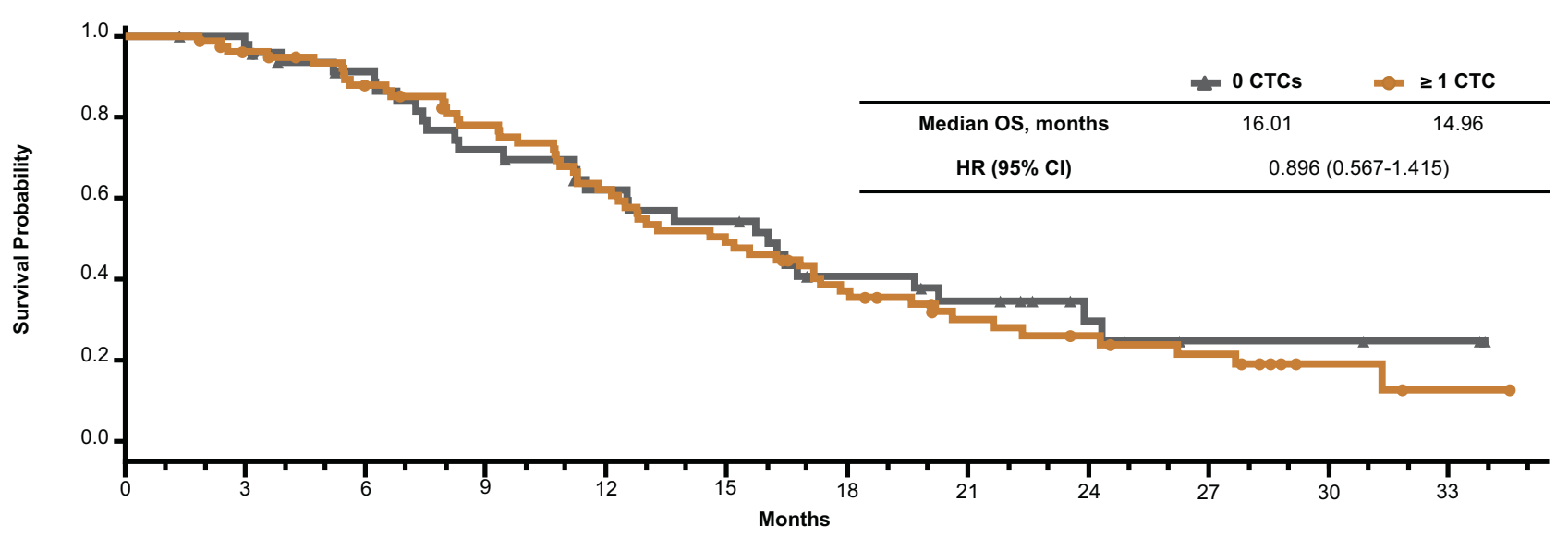

Figure 2 Efficacy outcomes by the absence or presence of circulating tumor cells at baseline. Kaplan-Meier plots of (A) PFS and (B) OS. Abbreviations: CTC, circulating tumor cell; HR, hazard ratio; OS, overall survival; PFS, progression-free survival.

detection method, a cutoff of $\geq 1$ CTC was used for the main analysis. Among the 3 cutoffs, the $\geq 1-C T C$ cutoff analysis included the largest number of patients $(n=24)$ in

Table 4 PFS by Treatment Arm and Change in Circulating Tumor Cell (CTC) Levels from Baseline in the Main Analysis of $\geq I$ CTC

\begin{tabular}{|l|l|l|l|}
\hline Treatment & CTC Group & n (\%) & $\begin{array}{l}\text { Median PFS, } \\
\text { Months }\end{array}$ \\
\hline nab-P/C & Group I (++ +) & $4(8.9)$ & NE \\
& Group 2 (+ \pm \pm$)$ & $27(60.0)$ & 8.94 \\
& Group 3 (-) & $14(31.1)$ & 4.37 \\
\hline \multirow{2}{*}{ nab-P/G } & Group I (++ +) & II (28.2) & 4.24 \\
& Group 2 (+ \pm \pm$)$ & II (28.2) & 7.92 \\
& Group 3 (-) & $17(43.6)$ & 8.75 \\
\hline \multirow{2}{*}{ G/C } & Group I (++ +) & $9(21.4)$ & 3.52 \\
& Group 2 (+ \pm \pm$)$ & $16(38.1)$ & 8.52 \\
& Group 3 (-) & $17(40.5)$ & 5.65 \\
\hline
\end{tabular}

Abbreviations: C, carboplatin; CTC, circulating tumor cell; G, gemcitabine; nab-P, nab-paclitaxel; NE, not evaluable; PFS, progression-free survival.
Group 1. As the CTC threshold increased, fewer patients were included in Group 1; therefore, these analyses were considered more cautiously. It should be noted that results were generally consistent across CTC thresholds.

The ORR was lower among patients with no detectable CTCs at baseline compared with those with $\geq 1$ detectable CTC. Although the differences in PFS and OS between these cohorts were small, the results were not aligned. However, the ORR, PFS, and OS results all suggest better outcomes among patients with CTC levels at baseline that were reduced or eliminated in subsequent cycles compared with CTC levels that persisted postbaseline. Therefore, within the limits of the system used in this study, the data suggest that the response of CTCs to treatment, rather than the presence or absence of CTCs per se, may predict outcomes.

We reported a decrease from baseline CTC levels with doublet chemotherapy in $>28 \%$ of patients; in particular, CTC clearance from baseline was noted in $60 \%$ of patients 
in the $n a b-\mathrm{P} / \mathrm{C}$ arm. A previous meta-analysis using CELLSEARCH CTC enumeration, which included 6 studies and $>800$ patients with MBC showed that $\geq 5 \mathrm{CTCs} /$ $7.5 \mathrm{~mL}$ at baseline and persistently elevated levels during treatment were associated with the worst PFS and OS outcomes, irrespective of type and line of treatment. ${ }^{13}$ In a larger, pooled analysis of $>1900$ patients with $\mathrm{MBC}$, the $\geq 5$-CTC threshold at baseline and increased CTC levels after baseline were significantly correlated with decreased PFS and OS compared with baseline levels of $<5$ CTCs. ${ }^{7}$ Similar findings emerged from the large, prospective, randomized study SWOG S0500 (also based on the CELLSEARCH platform), in which patients with TNBC and low CTC levels at baseline, as well as those who had CTC clearance with chemotherapy treatment, had a longer OS compared with those who had elevated CTC levels at baseline and after treatment. ${ }^{10}$ In addition, treatment with chemotherapy reduced baseline CTC levels in 55\% of patients with TNBC. However, changing to an alternative chemotherapy regimen based on CTC levels did not improve survival outcomes in the patients with $\mathrm{MBC}$ evaluated in the SWOG S0500 study.

The publication of CTC studies with conflicting results regarding treatment outcomes is acknowledged. For example, a meta-analysis of 50 studies and $>6700$ patients demonstrated that systemic therapy, whether single-agent or combination treatment in the neoadjuvant, adjuvant, or metastatic setting, reduced CTC levels in patients with breast cancer overall, ${ }^{14}$ but the CTC reduction appeared to be limited to patients with HER2+/- disease. However, in addition to including several different CTC platforms, the biology of the breast cancers included in this meta-analysis varied and included multiple disease settings (eg, early stage vs advanced) and subtypes (eg, only 2 TNBC studies [of which only 1 was in the metastatic setting]). In addition, a prospective study in TNBC comparing CELLSEARCH and immunomagnetic enrichment/flow cytometry methods revealed an association between baseline CTC levels and OS but not time to progression, and changes in CTC levels during chemotherapy were significantly associated with both time to progression and OS, regardless of the enumeration platform. ${ }^{15}$

The present study has potential limitations that must be considered. First, the CELLSEARCH platform relies on the capture of CTCs based on epithelial cell adhesion molecule (EpCAM) expression and excludes populations of low- or non-EpCAM-expressing cells in circulation. As a result, if tumor cells have undergone epithelial to mesenchymal transition, CTC detection may be less precise, as CTCs in TNBC often lack EpCAM expression and exhibit more stem celllike properties. ${ }^{1,16}$ In addition, it is possible that the proportion of epithelial cells relative to cells that underwent an epithelial to mesenchymal transition changed during treatment. Therefore, the perceived clearance may be the result of a population of CTCs that became undetectable. ${ }^{17,18}$ Second, we acknowledge that the small number of CTC patient samples $(\mathrm{N}=126)$ limits the ability to draw definitive conclusions, as this study was not powered to assess the outcomes investigated within. Additional studies including more patient samples are warranted.

\section{Data Sharing}

Data requests may be submitted to Celgene at www. CelgeneClinicalDataSharing.com and must include a description of the research proposal.

\section{Acknowledgments}

This work was supported by Celgene Corporation (no grant number applies). Medical writing assistance was provided by Mihaela Marina, $\mathrm{PhD}$, of MediTech Media, Ltd, funded by Celgene Corporation. This paper was presented at the 2018 American Association for Cancer Research (AACR) Annual Meeting as a poster presentation with interim findings. The poster abstract was published in Cancer Res. 2018;78(13 Suppl):Abstract 4209.

\section{Author Contributions}

MCL, WJ, VG, DAY, and NH contributed to data collection. XW analyzed the data. All authors interpreted the data and revised the report critically. All authors reviewed and approved the final version of the report to submit for publication. All authors agreed to be accountable for all aspects of the work and to ensure that questions related to the accuracy or integrity of any part of the work are appropriately investigated and resolved.

\section{Disclosure}

Dr Liu reports nonfinancial support from MediTech Media during the conduct of the study, her institution received funding from Celgene to conduct the trial. Dr Liu had received clinical trial support from Eisai, Genentech, GRAIL, Janssen, Merck, Novartis, Seattle Genetics and Tesaro. Dr Liu also received nonfinancial support from Ionis, nonfinancial support from Pfizer, nonfinancial support from Syndax, nonfinancial support from Agena, nonfinancial support from Cynvenio, and nonfinancial support from Menarini Silicon Biosystems outside the submitted work. Dr Janni reports grants from Celgene 
during the conduct of the study. Dr Yardley reports grants from Novartis during the conduct of the study. Sarah Cannon, the institution for which Dr Yardley serves as a research leader, has been paid for consulting/advisory roles from the following companies: Abraxis, Amgen, Alexion, Astellas, AstraZeneca, Bayer, Boehringer Ingelheim, Bristol-Myers Squibb, Celgene, Eisai, Lilly, Roche/Genentech, Gilead, GlaxoSmithKline, Janssen, Luitpold, Medivation, Novartis, Otsuka, Pfizer, ProStrakan, Spectrum, Janssen, Ipsen, Novartis, R-Pharm US, Millennium, Seattle Genetics, Sanofi, Merck, Merrimack, AbbVie, Incyte, Concordia, Genzyme, Exelixis, Nippon Kayaku, Odonate, ELM Medical, Biotheranostics, and Hengrui; and funding for the conduct of research projects has been provided by the following companies: AbbVie, Amgen, Astellas, AstraZeneca, Bayer, BioMarin, BristolMyers Squibb, Celgene, Concordia, Eisai, Exelixis, Genentech, Genzyme, GlaxoSmithKline, ImClone, Incyte, Ipsen, Janssen, Lilly, MedImmune, Medivation, Merck, Merrimack, Novartis, Pfizer, Roche, Sanofi, Spectrum, and Tesaro. Dr Harbeck reports personal fees from Celgene during the conduct of the study. Mr McGovern, Mr Beck and Dr Wei reports employment and stock options from Celgene during the conduct of the study. The authors report no other conflicts of interest in this work.

\section{References}

1. Krebs MG, Hou JM, Ward TH, Blackhall FH, Dive C. Circulating tumour cells: their utility in cancer management and predicting outcomes. Ther Adv Med Oncol. 2010;2(6):351-365. doi:10.1177/ 1758834010378414

2. Pukazhendhi G, Gluck S. Circulating tumor cells in breast cancer. $J$ Carcinog. 2014;13:8. doi:10.4103/1477-3163.135578

3. Sparano J, O'Neill A, Alpaugh K, et al. Association of circulating tumor cells with late recurrence of estrogen receptor-positive breast cancer: a secondary analysis of a randomized clinical trial. JAMA Oncol. 2018;4(12):1700-1706. doi:10.1001/jamaoncol.2018.2574

4. Menarini Silicon Biosystems Inc. CellSearch Circulating Tumor Cell Kit. [Instructions for Use]. Huntingdon Valley, PA: Menarini Silicon Biosystems Inc; 2017.

5. Cristofanilli M, Budd GT, Ellis MJ, et al. Circulating tumor cells, disease progression, and survival in metastatic breast cancer. $N$ Engl J Med. 2004;351(8):781-791. doi:10.1056/NEJMoa040766
6. Hayes DF, Cristofanilli M, Budd GT, et al. Circulating tumor cells at each follow-up time point during therapy of metastatic breast cancer patients predict progression-free and overall survival. Clin Cancer Res. 2006;12(14 Pt 1):4218-4224. doi:10.1158/1078-0432.CCR-052821

7. Bidard F-C, Peeters DJ, Fehm T, et al. Clinical validity of circulating tumour cells in patients with metastatic breast cancer: a pooled analysis of individual patient data. Lancet Oncol. 2014;15(4):406-414. doi:10.1016/S1470-2045(14)70069-5

8. Liu MC, Shields PG, Warren RD, et al. Circulating tumor cells: a useful predictor of treatment efficacy in metastatic breast cancer. J Clin Oncol. 2009;27(31):5153-5159. doi:10.1200/JCO.2008.20.6664

9. Pierga JY, Hajage D, Bachelot T, et al. High independent prognostic and predictive value of circulating tumor cells compared with serum tumor markers in a large prospective trial in first-line chemotherapy for metastatic breast cancer patients. Ann Oncol. 2012;23 (3):618-624. doi:10.1093/annonc/mdr263

10. Smerage JB, Barlow WE, Hortobagyi GN, et al. Circulating tumor cells and response to chemotherapy in metastatic breast cancer: SWOG S0500. J Clin Oncol. 2014;32(31):3483-3489. doi:10.1200/ JCO.2014.56.2561

11. Yardley DA, Brufsky A, Coleman RE, et al. Phase II/III weekly $n a b$-paclitaxel plus gemcitabine or carboplatin versus gemcitabine/ carboplatin as first-line treatment of patients with metastatic triple-negative breast cancer (the tnAcity study): study protocol for a randomized controlled trial. Trials. 2015;16:575. doi:10.1186/ s13063-015-1101-7

12. Yardley DA, Coleman R, Conte P, et al. nab-Paclitaxel plus carboplatin or gemcitabine versus gemcitabine plus carboplatin as first-line treatment of patients with triple-negative metastatic breast cancer: results from the tnAcity trial. Ann Oncol. 2018;29(8):1763-1770. doi:10.1093/annonc/mdy201

13. Liu MC, Mego M, Nakamura S, et al. Clinical validity of circulating tumor cells (CTC) enumeration in 841 subjects with metastatic breast cancer (MBC). J Clin Oncol. 2011;29(suppl 15):10592. [abstract 10592]. doi:10.1200/jco.2011.29.15_suppl.10592

14. Yan WT, Cui X, Chen Q, et al. Circulating tumor cell status monitors the treatment responses in breast cancer patients: a meta-analysis. Sci Rep. 2017;7:43464. doi:10.1038/srep43464

15. Magbanua MJ, Carey LA, DeLuca A, et al. Circulating tumor cell analysis in metastatic triple-negative breast cancers. Clin Cancer Res. 2015;21(5):1098-1105. doi:10.1158/1078-0432.CCR-14-1948

16. Yang MH, Imrali A, Heeschen C. Circulating cancer stem cells: the importance to select. Chin J Cancer Res. 2015;27(5):437-449. doi:10.3978/j.issn.1000-9604.2015.04.08

17. Bulfoni M, Gerratana L, Del Ben F, et al. In patients with metastatic breast cancer the identification of circulating tumor cells in epithelial-to-mesenchymal transition is associated with a poor prognosis. Breast Cancer Res. 2016;18(1):30. doi:10.1186/s13058016-0687-3

18. Yu M, Bardia A, Wittner BS, et al. Circulating breast tumor cells exhibit dynamic changes in epithelial and mesenchymal composition. Science. 2013;339(6119):580-584. doi:10.1126/science.1228522
Cancer Management and Research

\section{Publish your work in this journal}

Cancer Management and Research is an international, peer-reviewed open access journal focusing on cancer research and the optimal use of preventative and integrated treatment interventions to achieve improved outcomes, enhanced survival and quality of life for the cancer patient.
The manuscript management system is completely online and includes a very quick and fair peer-review system, which is all easy to use. Visit http://www.dovepress.com/testimonials.php to read real quotes from published authors. 